\title{
FORECASTING FOREIGN TOURIST ARRIVALS TO INDIA USING TIME SERIES MODELS
}

\author{
Shalini Chandra ${ }^{1}$, Kriti Kumari* \\ ${ }^{1}$ Department of Mathematics and Statistics, Banasthali Vidyapith \\ *Department of Mathematics and Statistics, Banasthali Vidyapith
}

\begin{abstract}
This study aims to compare various quantitative models to forecast monthly foreign tourist arrivals (FTAs) to India. The models which are considered here include vector error correction (VEC) model, Naive I and Naive II models, seasonal autoregressive integrated moving average (SARIMA) model and Grey models. A model based on combination of single forecast values using simple average (SA) method has also been applied. The forecasting performance of these models have been compared under mean absolute percentage error (MAPE) and U-statistic ( $\mathrm{U}_{\text {stat }}$ ) criteria. Empirical findings suggest that the combination model gives better forecast of FTAs to India relative to other individual time series models considered here.
\end{abstract}

Keywords:Foreign tourist arrivals, Time series models, Forecast comparisons.

\footnotetext{
* Corresponding author: Kriti Kumari

Email:kriti.kri89@gmail.com
} 


\section{Introduction}

Tourism is one of the most essential sectors which has direct impact on the financial and economic development of India. World Tourism Organization (2014) reported that India is the top seventh tourism earners among Asian and Pacific countries. As per the World Travel and Tourism Council (2017) statistics, India owes a lot to tourism by providing job opportunities (9.3\% of its total jobs) and for contribution to its national income (9.6\% of the nation's GDP in 2016).

The number of foreign tourist arrivals (FTAs) in India is an increasing quantity over the past few years. Annual report of Ministry of tourism, Government of India, 2016 reported 10.2\% growth in year 2013-14 while it was 5.9\% during 2012-13. Also, the growth rate of $4.5 \%$ and $10.7 \%$ has been noticed in FTAs in India during 2014-15 and 2015-16, respectively. According to Indian Tourism Statistics (2015) report USA, Bangladesh, United Kingdom, Sri Lanka, Canada, Malaysia, Australia, Germany, France and Japan are top ten source countries for FTAs in India (see Figure 1). About 62.52\% of total FTAs in India during 2015 have been accounted by these top ten countries and of which $15 \%$ is contributed by US only. Therefore, from the perspective of international trade in India, tourism industry development is very important which contributes significantly to foreign exchange earnings and other economic variables. Tourism demand forecasting, or specifically air travel demand forecasting, hence become essential for the policy makers of tourism industry.

Time series modeling and forecasting(Lai (2005), Awale (2017)have an effective impact in the planning of all activities of the tourism industry and it also defines the relationship with other factors contributing to tourism demand. There exist several methods to analyze the relationship between tourism and their determining factors. For instance, Kim (1988) and Lee et al. (1996) employed classical regression analysis to measure the effects of exchange rate, trade volume, relative price and income level on inbound tourism in Korea. They observed that their models estimated by the ordinary least squares (OLS) suffer from the problem of serial correlation in residuals giving rise to imprecise estimates. However, Granger and Newbold wayback in 1974 pointed out that in the case of non-stationary variables, conventional method of estimation may lead to spurious regression thereby leading to biased and imprecise results. To overcome the difficulty, Engle and Granger (1987) introduced co-integration analysis to study long run equilibrium among non-stationary variables having common trend. Approaches involving co- integration analysis have been consistently used as an important tool with a set of variables to forecast. In particular, error-correction model has been commonly applied in modeling and forecasting of foreign tourist arrivals in determining long- run relationships involving two economic variables in a single equation framework. Moreover, the vector error correction (VEC) model has also been widely applied to estimate more than one co-integrating relationships for a set of time series variables. For instance, Kim and Song (1998) applied the co-integration and error correction method to measure the long-run and short-run effects of inter- national tourism demand in South Korea from four source countries, Japan, US, UK, and Germany. Lee and Chung (1995) provided the long-run relationship among income, interest rate, and exchange rate by applying co-integration analysis. Salman (2003) employed co-integration analysis to examine the long-run effects of income, price, exchange rate, the Chernobyi nuclear accident and the 1991 Gulf WAR on monthly tourist arrivals to Sweden from USA, European and Scandinavian countries. Recently, Akay and Teke (2017) estimate the effect of the exchange rate and income on Turkish tourism for the quarterly data for the period 1998-2011 using co-integration approach. 
In recent times, various studies on forecasting tourist arrivals have applied quantitative time series models and forecasting techniques such as Naive I \& Naive II (see Martin and Witt (1989), Law and Au (1999), Law (2000)), autoregressive integrated moving average (ARIMA), seasonal ARIMA (SARIMA) (Lim and McAleer (1999, 2002), Cho (2003), Coshall (2006), Samagaio and Wolters (2010), Nguyen et al. (2013), Apergis et al. (2017)) and Grey models. Among various time series models, SARIMA model was found to be the best fitted model to study tourist arrivals because of the presence of seasonality in FTA series. Chu (1998) employed SARIMA model for tourism demand in Asian-Pacific countries. The results show that the performance of SARIMA model was effectively superior to Naive I \& Naive II models. Chen et al. (2009) compared the accuracy of SARIMA model with Holt-Winters and Grey model to forecast inbound air travel arrivals for Taiwan. They found that SARIMA model is the best one for forecasting tourism demand as compared to other forecasting models.

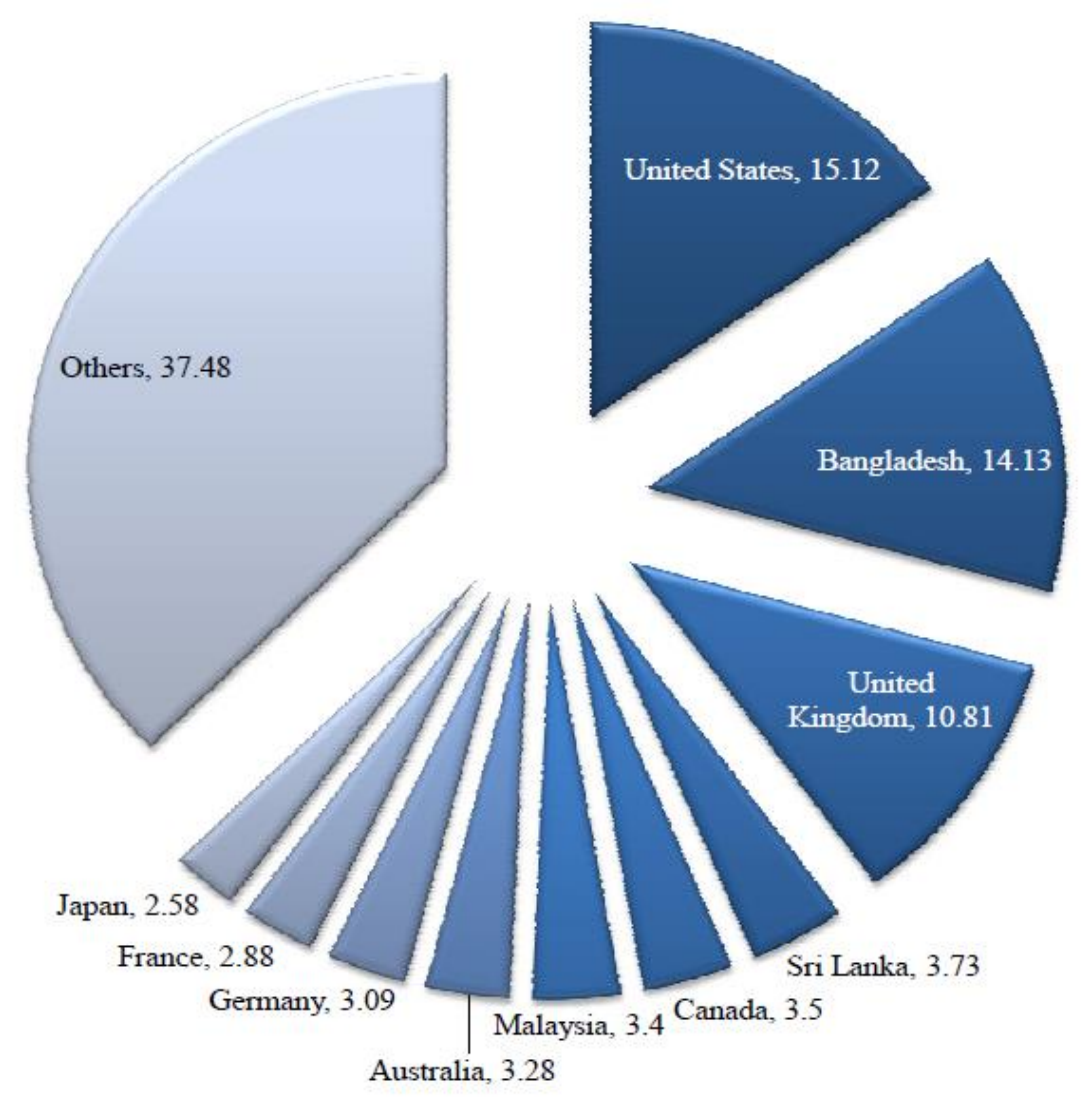

Figure 1: Market share of FTAs in 2015.

In addition, there has been a growing interest among the researchers in the comparison of error correction and time series models for tourism demand forecasting. A vast variety of literature is available to study the comparative analysis of error correction and time series models. For instance, Song et al. (2000) studied the out-of sample forecasts of outbound tourism demand in the UK using error correction, Naive and ARIMA models. They found that the forecasting performance of error correction model is better than that of other time series models. Moreover, Li et al. (2006) compared the time varying parameter, error correction and time series models to forecast the tourism demand of five Western European tourists destinations using mean absolute percentage error and mean absolute error criteria. They argued that forecasting accuracy of error correction models was better than that of time series models. Although, Kulendran and King (1997) empirically showed that the performance of the time series models was superior to the error correction model to forecast 
quaterly tourist arrivals to Australia. However, Song et al. (2003) demonstrated that the forecasting performance of error correction and ARIMA models was poor as compared to time varying parameter and other quantitative models to forecast the international tourism demand in Denmark.

However, it is believed that the combination of forecast values obtained from various time series models may improve the performance of forecasting. There- fore, Bates and Granger (1969) developed combination of forecasts by using the various combination methods in order to improve the single forecasts accuracy. It provides reliable and accurate forecasting results than individual models. For example, Menezes et al. (2000) and Song and Li (2008) applied combination of forecasts based on simple average method. They found that the performance of the combination method was better than that of individual forecasts.

To the best of our knowledge, researchers in India have not paid much attention to study the forecasting performance of FTAs to India using various quantitative models, though tourism industry in India has shown a significant growth in past few years. In this paper, an attempt has been made to forecast foreign tourist arrivals in India using econometric and time series models. To investigate the long-run relationship among various factors like exchange rate, foreign exchange earnings and tourists arrivals from USA, affecting FTAs to India, the monthly data were obtained from the site http://www.indiastat.com, Ministry of Tourism, Govt of India for the period of Jan. 2003 to Dec. 2016. In addition, various time series models will be fitted including Naive I \& Naive II, SARIMA Grey and SA. The forecasting performances of various models have also been compared under mean absolute percentage error (MAPE) and U-statistic $\left(\mathrm{U}_{\text {stat }}\right)$ criteria.

The plan of the paper is as follows. Section 2 discusses the important factors related to the study of foreign tourist arrivals to India. Section 3 describes the data, methodology, and the results of co-integration and time series analysis obtained from empirical study. Section 4 presents the comparison of forecasting performance of various models under the MAPE and $\mathrm{U}_{\text {stat }}$ criteria. The concluding remarks are given in the last section. 


\section{Tourism factors}

Foreign tourist arrivals depend on various variables like exchange rate, foreign exchange earnings, tourist prices, tourist expenditures, transportation cost etc. Due to the difficulties in collecting data for variables like tourism prices, tourist expenditures, transportation cost, data only on exchange rate (EXR), foreign exchange earnings (FEEs) and number of tourist arrivals from USA(USAFTAs), are used to forecast FTAs in India. The exchange rate and foreign exchange earnings are closely linked with FTAs and they play an important role in the economic growth of India. Another important variable, which is closely associated, is the tourist arrivals from USA. Indian Tourism Statistics (2015) reported that among the top 10 countries, USA contributed the maximum number (see Figure 1) of foreign tourist arrivals in India. Thus, the three independent variables considered in this study affecting FTAs in India are EXR, FEEs and USAFTAs. Figure 2 and 3 present the time series plots of FTAs and other considered variables. The plots show that FTAs, FEEs and USAFTAs have increasing trend along with the seasonal components. However, Figure 3 gives a vague idea of the presence of increasing trend in EXR series with no seasonal component.

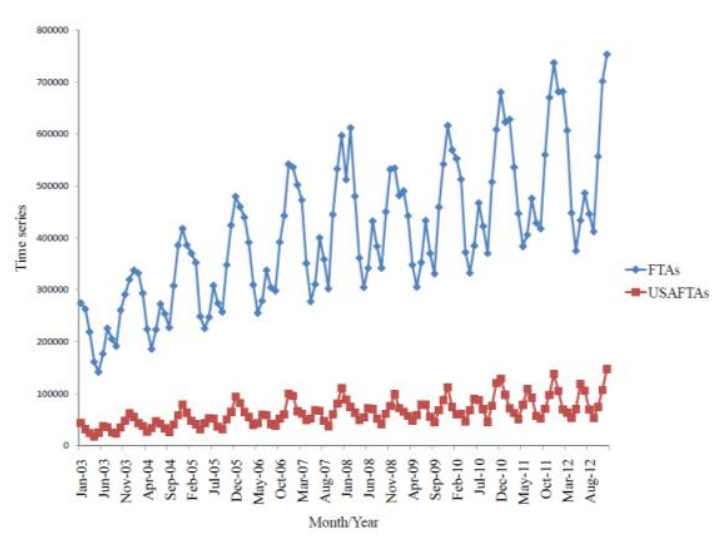

Figure 2: Time series plots of FTAs and USAFTAs.

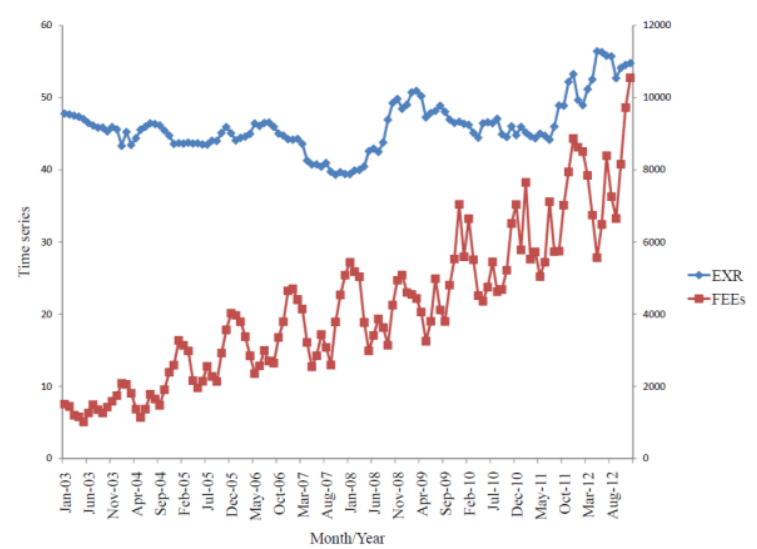

Figure 3: Time series plots of EXR and FEEs. 


\section{Models and empirical results}

The study employs monthly time series data of foreign tourist arrivals (in numbers), exchange rate (in Rs. per unit of US dollars), foreign exchange earnings (Rs. in crore) and tourist arrivals from USA (in numbers) from January 2003 to December 2016 in India. Time series data are obtained from the site http://www.indiastat.com, Ministry of Tourism, Govt of India. The time series data is divided into two periods (1) 2003:1-2012:12, consists of 120 observations used to estimate the individual models; (2) data of 2013:1-2016:12 are used to generate the out-of-sample forecasts for different models. The R-3.0.3 software is used for the overall empirical analysis.

\subsection{Co-integration analysis}

In this section, we will provide results of co-integration analysis to obtain VEC models to forecast FTAs. In order to perform co-integration analysis, unit root (seasonal and nonseasonal) test has been applied to FTAs, EXR, FEEs and USAFTAs. The standard HEGY test (Hylleberg et al. (1990)) is applied for the testing of seasonal unit root in seasonally adjusted data to avoid biased results due to the wrong choice of a transformation of the series and also, other consequences for the imprecise explanation. The results of the HEGY test along with the p-values in the parenthesis are reported in Table 1 for all the four series. It shows that the null hypothesis of a unit root for FTAs, EXR, FEEs and USAFTAs cannot be rejected at zero frequency indicating that all the series considered here are integrated of order one. Though, it is not always necessary that there will be no seasonal unit root in the seasonally adjusted series, yet in all the four series we found none at $10 \%$ level of significance. Since all the variables are of the same order, co-integration analysis can be performed to study long run relationships among variables.

Table 1: Results of HEGY test

\begin{tabular}{lcccc}
\hline \multicolumn{1}{c}{ Unit roots } & FTAs & EXR & FEEs & USAFTAs \\
\hline$\pi_{1}$ & $-2.329(0.10)$ & $-1.745(0.10)$ & $0.008(0.10)$ & $-1.155(0.10)$ \\
$\pi_{2}$ & $-3.378(0.01)$ & $-3.370(0.01)$ & $-3.739(0.01)$ & $-2.178(0.024)$ \\
$\pi_{3: 4}$ & $7.893(0.01)$ & $17.763(0.01)$ & $6.686(0.01)$ & $7.624(0.01)$ \\
$\pi_{5: 6}$ & $8.403(0.01)$ & $16.006(0.01)$ & $7.864(0.01)$ & $5.381(0.01)$ \\
$\pi_{7: 8}$ & $8.582(0.01)$ & $9.820(0.01)$ & $6.673(0.01)$ & $2.410(0.094)$ \\
$\pi_{9: 10}$ & $9.016(0.01)$ & $16.220(0.01)$ & $4.041(0.018)$ & $8.506(0.01)$ \\
$\pi_{11: 12}$ & $6.305(0.01)$ & $5.599(0.01)$ & $3.197(0.042)$ & $2.398(0.094)$ \\
\hline
\end{tabular}

Johansen and Juselius (1990) and Johansen (1991) and maximum likelihood (ML) estimation method is used to estimate the long-run relationships among FTAs, EXR, FEEs and USAFTAs. The Johansen method consists of estimating vector autoregression (VAR) model for a set of different time series variables; dependent and independent I(1) variables. Johansen developed a system of equations method, which helps in providing tests for the existence of multiple co-integrating vectors. In a Johansen procedure, lag order is chosen by Akaike information criterion (AIC) (Pantula et al. (1994)). The Akaike information criterion (AIC) is a measure of the relative quality of a statistical model, for a given set of data. The expression for AIC is given by:

$$
\mathrm{AIC}=2 \mathrm{k}-2 \ln (L)
$$

where, $\mathrm{k}$ is the number of parameters in the statistical model, and $\mathrm{L}$ is the maximized value 
of the likelihood function for the estimated model. Then the trace test statistic is computed to test the significance of number of co-integrating equations. The results of test statistic at $1 \%$ and 5\% significance levels are reported in Table 2. From the results of co-integration, we observe that for testing $H_{0}^{0}: r=0$, value of test statistic is greater than the critical value $(\mathrm{CV})$ at $5 \%$ level of significance. Hence, the null hypothesis $\left(H_{0}^{0}\right)$ of no co-integration is rejected in favor of alternative hypothesis of co-integration. Similar tests have been conducted to test the presence of one; two and three co-integrating equations and the results obtained are reported in Table 2 which indicates the presence of at the most two co-integrating relations among tourism variables. Since we aim to forecast FTAs, the normalized co-integrating relation involving the three Indian tourism variables with respect to FTAs is reported only, which is given below.

Table 2: Results of co-integration test

\begin{tabular}{cccc}
\hline$H_{0}^{0}$ & Roots & Statistic & CV \\
\hline $\mathrm{r}=0$ & 0.2826 & 82.42 & 62.99 \\
$\mathrm{r}=1$ & 0.2155 & 43.22 & 42.44 \\
$\mathrm{r}=2$ & 0.0783 & 14.58 & 25.32 \\
$\mathrm{r}=3$ & 0.0411 & 4.96 & 12.25 \\
\hline
\end{tabular}

$$
\text { FTAs }=303814.2-4440.3 E X R+27.1 F E E s+3.1 U S A F T A s
$$

The above equation indicates the existence of co-integrating long-run relationship among FTAs, EXR, FEEs and USAFTAs and the variables appear in the equation with the correct sign. Now, the vector error correction (VEC) model will be estimated for FTAs. VEC is one of the most commonly applied multivariate econometric model to forecast time series data by utilizing more than one co-integrating relationships for a set of time series variables developed by Engle and Granger (1987). The first step in constructing a VEC model is fitting a vector autoregression (VAR) model for a set of $\mathrm{K}$ time series variables $X_{t}=\left(X_{1 t}, X_{2 t}, \cdots\right.$, $\left.X_{K t}\right)^{\prime}$. The VAR model of order $\mathrm{p}$ is given by

$$
X_{t}=E_{1} X_{t-1}+E_{2} X_{t-2}+\cdots+E_{p} X_{t-p}+u_{t}, t=1, \ldots, \mathrm{T}
$$

where, $E_{i}(i=1,2, \ldots, p)$ are $(K \times K)$ coefficient matrices and $u_{t}=\left(u_{1 t}, u_{2 t}, \ldots, u_{K t}\right)^{\prime}$ is assumed to be a vector of random error.

Now, the VEC model is obtained from the VAR by subtracting $X_{t-1}$ from both sides and rearranging the terms. The form of VEC model can be written as

$$
\Delta \mathrm{X}_{\mathrm{t}}=\Pi \mathrm{X}_{\mathrm{t}-1}+\Gamma_{1} \Delta \mathrm{X}_{\mathrm{t}-1}+\cdots+\Gamma_{\mathrm{P}-1} \Delta \mathrm{X}_{\mathrm{t}-\mathrm{P}+1}+\mathrm{u}_{\mathrm{t}}
$$

where, $\Pi=-\left(I_{k}-A_{1}-\cdots-A_{P}\right), \Gamma_{i}=-\left(A_{i+1+\cdots+A_{P}}\right)$ for $\mathrm{i}=1, \cdots, \mathrm{p}-1$ and $u_{t}$ is the error term. Also, the parameters involved in the model can be estimated using the ordinary least squares (OLS) method.

The order of VEC model has been selected on the basis of minimum AIC value. AIC results for the six lags are reported in Table 3. In the VEC model, the error correction term (ECT) is included which tells how far things deviate from long run equilibrium and the estimated results of VEC model is reported in Table 4 with the values of $t$ statistics in parenthesis. It can be noticed that coefficient of ECT is found to be significant and negative in the equation at $5 \%$ level of significance indicating long run equilibrium relationship among 
variables. The lags of FTAs, exchange rates, foreign exchange earnings and USAFTAs are included in VEC model. However, only significant terms are retained in the estimated equation with the non-significant terms being deleted first.

The robustness of the VEC model is evaluated by employing the Durbin Watson (DW) test to check the significance of autocorrelation in the error terms. The calculated Durbin Watson (DW) test statistic of the residuals compared with the critical values given in the DurbinWatson tables reveals that there is no autocorrelation. Engle(1982) autoregressive conditional heteroscedasticity(ARCH) LM test is applied to test the problem of heteroscedasticity in residuals. The calculated chi square value of ARCH LM test comes out to be 6.3877 with pvalue of 0.0942 which implies the absence of heteroscedasticity.

Table 3: Selection of lag order for VEC model

\begin{tabular}{cc}
\hline Number of lags & AIC criterion \\
\hline 1 & 5698.144 \\
2 & 5665.936 \\
3 & 5618.562 \\
4 & 5576.01 \\
5 & 5535.977 \\
6 & 5504.039 \\
\hline
\end{tabular}

\subsection{Time series models}

Time series models have also been commonly used models for forecasting non-stationary time series data along with the trend and seasonal factors. It includes the Naive I \& Naive II, SARIMA and Grey models. Here it is proposed to evaluate forecasting performance of these models with that of VEC model and suggest best fitted model to FTAs to India. The empirical analysis of these models is given in the following subsections.

Table 4: Estimated VEC model

\begin{tabular}{lc}
\hline \multicolumn{1}{c}{$\begin{array}{c}\text { Independent } \\
\text { variables }\end{array}$} & Coefficients \\
\hline Costant & $95474.3(40265.2)^{*}$ \\
$\Delta$ FTAs $_{\mathrm{t}-1}$ & $-0.3011(0.1622)^{*}$ \\
$\Delta$ USAFTAs $_{\mathrm{t}-1}$ & $-1.0181(0.3984)^{*}$ \\
$\Delta$ USAFTAs $_{\mathrm{t}-2}$ & $-1.3926(0.3993)^{*}$ \\
$\Delta$ USAFTAs $_{\mathrm{t}-4}$ & $-0.9902(0.3961)^{*}$ \\
$\Delta \mathrm{EXR}_{\mathrm{t}-6}$ & $4597.0493(1766.8995)^{*}$ \\
ECT $_{\mathrm{t}-1}$ & $-0.7042(0.1547)^{*}$ \\
DW & 1.94 \\
\hline
\end{tabular}

\subsubsection{Naive model}

Two different Naive methods of forecasting are quite popular for time series data. The first method is Naive I and second method is Naive II. In Naive I method, each forecast is generated by using the previous value of time series data, for instance, the forecast value of FTAs for January, 2013 is the arrivals figure of December, 2012 likewise the forecast for February, 2013 is the arrivals figure of January, 2013. Similarly, the forecast values of rest of the time points can be obtained for foreign tourist arrivals using Naive I method. In Naive II method, forecast of January, 2013 is equal to the figure obtained in December, 2012 
multiplied by the growth rate of January, 2013 over December, 2012.

\subsubsection{Estimated SARIMA model}

Box-Jenkins (1976) introduced SARIMA model for modeling a time series with the trend and seasonal component. It is the combination of non-seasonal and seasonal autoregressive (AR) and moving average (MA) models. SARIMA model for a time series, say $X_{t}(t=$ $1,2 \cdots T)$, is given by

$$
\phi_{P}(B) \Phi_{P}\left(B^{s}\right) \Delta^{d} \Delta_{s}^{D} X_{t}=\theta_{q}(B) \Theta_{Q}\left(B^{s}\right) a_{t}, t=1,2, \cdots T
$$

where,

$$
\begin{gathered}
\phi_{P}(B)=1-\phi_{1} B-\cdots-\phi p B^{P}, \\
\Phi_{P}\left(B^{s}\right)=1-\Phi_{1} B^{s}-\cdots-\Phi_{P} B^{P s} \\
\theta(B)=1+\theta_{1} B+\cdots+\theta_{q} B^{q} \\
\Theta(B)=1+\Theta_{1} B^{s}+\cdots+\Theta_{Q} B^{Q s}, \\
\Delta^{d} \Delta_{s}^{D} X_{t}=(1-B)\left(1-B^{s}\right) X_{t}
\end{gathered}
$$

are non-seasonal and seasonal AR and MA models, respectively $B$ is the backshift operator, $\phi_{P}<1, \Phi_{P}<1, \theta_{q}<1, \Theta_{Q}<1$ and $\mathrm{a}_{\mathrm{t}} \sim$ white noise $\left(0, \sigma^{2}\right)$.

SARIMA model is usually represented in multiplicative form such as SARIMA (p, d, q) $\times$ $(\mathrm{P}, \mathrm{D}, \mathrm{Q}) \mathrm{s}$, where $(\mathrm{p}, \mathrm{P})$ and $(\mathrm{q}, \mathrm{Q})$ indicate the seasonal and nonseasonal order of AR and MA, respectively, with seasonal periods s, non-seasonal difference $(\mathrm{d})$ and seasonal difference $(\mathrm{D})$.

In this study seasonal ARIMA is fitted to stationary series after eliminating trend and seasonality component from the series at level. Differencing is one of the methods used frequently to obtain stationary series. Here the deseasonalised FTAs series is transformed to stationary series using first difference $(\mathrm{d}=1)$. The orders of seasonal and non-seasonal autoregressive (AR) and moving average (MA) models have been identified by autocorrelation and partial autocorrelation functions. Further, the best model fitted to the series is selected corresponding to minimum Akaike's information criterion (AIC). From Table 5 it is noticed that $(1,1,2)(1,0,2)_{12}$ is the best fitted SARIMA model for FTAs series according to the minimum AIC. Statistical independence of residuals is examined via BoxPierce Q-statistic (Ljung and Box (1978)) for all lags and it is found that the null hypothesis of independence of residuals is not rejected, The results of Box- Pierce Q-statistic are presented in Table 6 . Hence, SARIMA $(1,1,2)(1,0,2)_{12}$ is considered to be an adequate model for out-of-sample forecasts of FTAs.

Table 5: Fitted SARIMA models

\begin{tabular}{cc}
\hline Models & AIC criterion \\
\hline$(1,1,2)(1,0,2)_{12}$ & 2660.34 \\
$(2,1,1)(2,0,1)_{12}$ & 2664.98 \\
$(1,1,2)(2,0,1)_{12}$ & 2660.41 \\
$(0,1,2)(2,0,1)_{12}$ & 2661.28 \\
\hline
\end{tabular}

\subsubsection{Grey model}

So far we noticed that the error-correction models and SARIMA models require certain assumption on distribution owing to the fact that they have certain statistical limitations. 
However, there exist some quantitative models to forecast time series data which are free from any distributional assumptions such as Grey model developed by Deng (1982). In this model, future trend is estimated using linear differential equation of order one. The parameters involved in the model can be estimated using the ordinary least squares (OLS) method (see Wang (2004) and Xu et al. (2016)). The Grey model of first order linear differential equation is written as

$$
\frac{\mathrm{dX}_{(t)}}{d t}+a X_{(t)}=b
$$

where $X_{t}$ is a time series and a $\& \mathrm{~b}$ are the parameters. The posterior variance ratio (PVR) criterion is used to check the accuracy of Grey model. Posterior variance ratio $(\mathrm{C})$ is the ratio of the standard deviations of the actual time series and the residual series (Nguyen et al. (2013)). The equation of PVR is given by the ratio

$$
\mathrm{C}=\frac{S_{2}}{S_{1}}
$$

where,

$\mathrm{S}_{2}=$ standard deviation of residuals series

$\mathrm{S}_{1}=$ standard deviation of actual series.

According to Deng (1986), the value of posterior variance ratio $(C)<0.35$ indicates high accuracy of Grey model. However, when it is $<0.5$ model is called qualified, and when $\mathrm{C}<$ 0.65 model is said to be just qualified. Also, model is said to be unqualified when $C \geq 0.65$. Further, the estimated values of the parameters a \& b for Grey model are -0.006628205 and 266972.1 , respectively. The calculated value of $C$ which is 0.2202 indicates the high accuracy of Grey model.

Since a combination of forecasts provide more accurate forecast value than single forecasts. Therefore, in the next subsection simple average method to combine the forecasts values is briefly defined.

Table 6: Values of Box-Pierce statistic

\begin{tabular}{ccccccccc}
\hline Lags & 1 & 2 & 3 & 4 & 5 & 6 & 7 & 8 \\
\hline statistic value & 0.04 & 0.21 & 0.21 & 0.52 & 1.39 & 2.13 & 2.15 & 2.63 \\
p-value & 0.8 & 0.8 & 0.9 & 0.9 & 0.9 & 0.9 & 0.9 & 0.9 \\
\hline
\end{tabular}

\subsubsection{Combination approach: Simple average (SA) method}

Simple average is a combination method based on the average of forecasting values of different forecasting models. Suppose that $X_{1}^{\wedge}(t), X_{2}^{\wedge}(t), \ldots \ldots, X_{m}^{\wedge}(t)$ are m forecasts values of forecasting models, then the expression for simple average combination method is given by

$$
\frac{1}{n} \sum_{n=1}^{m} X_{m}^{\wedge}(t)
$$


The forecasting results of VEC, Naive I \& Naive II, SARIMA and Grey models are combined by using the simple average combination method which is given as below:

$$
\widehat{X_{t}}=0.5 \text { Naive } \mathrm{I}+0.5 \text { Naive II }+0.5 \mathrm{VEC}
$$

where equal weight has been given to all forecast values obtained from various models considered here.

\section{Evaluating forecasting performance}

The forecasting performance of all the fitted models has been evaluated under mean absolute percentage error (MAPE) and U-statistic $\left(U_{\text {stat }}\right)$ criteria, which are given as follows:

$$
\begin{aligned}
& \text { MAPE }=\frac{1}{n} \sum_{t=1}^{n}\left(\frac{\left|X_{t}-\widehat{X_{t}}\right|}{X_{t}}\right) \times 100 \\
& U_{\text {stat }}=\frac{\sqrt{\frac{1}{n} \sum_{t=1}^{n}\left(X_{t}-\widehat{X_{t}}\right)^{2}}}{\sqrt{\frac{1}{n} \sum_{t=1}^{n} \widehat{X}_{t}^{2}}+\sqrt{\frac{1}{n} \sum_{t=1}^{n} X_{t}^{2}}}
\end{aligned}
$$

where $\mathrm{n}$ is sample size, $X_{t}$ is actual value of the time series data and $\widehat{X_{t}}$ is the forecast value in the $\mathrm{t}^{\text {th }}$ month.

Lewis (1982) showed that the value of MAPE being less than $10 \%$ indicates the high accuracy of forecasting. When it lies between 10-20\% forecasting is considered to be good, $20-50 \%$ is reasonable and the value being more than $50 \%$ denotes inaccuracy in forecasting. It can be said that if the value of $U_{\text {stat }}$ is close to zero, the forecast model is considered to be good and $U_{\text {stat }}$ close to one indicates poor performance of the model ( see Goh and Law (2002)).

Note that the MAPE and $U_{\text {stat }}$ are the measures of the deviation between actual and forecasted values. Therefore, the forecasting performance is better when the values of these measures are lesser.

Table 7 shows the results of out-of-sample forecasting performance of VEC and time series models under MAPE and $U_{\text {stat }}$ criteria to forecast FTAs to India. The empirical analysis suggests that VEC and time series models have highly accurate forecasting performance since MAPE values are less than $10 \%$ for all the models considered here. This empirical findings are in tune with that of obtained by Kulendran and Witt (2001) and Li et al. (2006) where they have shown that error correction model outperforms the SARIMA model to forecast tourism demand in UK and five Western European tourists destinations. Furthermore, the combination method based on simple average of forecasts outperforms VEC, Naive models, SARIMA and Grey models to forecast FTAs data due to lesser MAPE and $U_{\text {stat }}$ values (see Table 7). This empirical result is similar to that of obtained by Song and Li (2008) where they found that the results of simple average based combination of forecasts outperforms individual forecasts. 


\begin{tabular}{llccccc} 
MAPE & 3.66 & 3.59 & 6.27 & 5.00 & 5.81 & 3.15 \\
$U_{\text {stat }}$ & 0.027 & 0.023 & 0.038 & 0.035 & 0.032 & 0.020 \\
\hline
\end{tabular}

\section{Conclusions}

The long run relationship among foreign tourist arrivals, exchange rate, for- eign exchange earnings and tourist arrivals from the USA in India using monthly time series data for the period of January 2003 to December 2016 using co- integration approach has been investigated. Vector error correction model is fitted to capture long run and short run equilibrium in variables. In addition, various time series models have also been fitted to forecast FTAs to India. The forecasting performance of VEC and time series models is compared under the MAPE and $\mathrm{U}_{\text {stat }}$ criteria. It can be noticed from the empirical findings that VEC model performs better than SARIMA, Naive II and Grey model when in- dividual forecast values are compared. However, combination method based on simple average provides improvement in the forecasting performance of the model used to forecast FTAs to India with minimum value of MAPE and $U_{\text {stat. }}$ Based on our empirical findings, we, therefore, conclude that between the vector error correction model and the SARIMA model, former is better than the later while combination approach gives better results than the individual time series models to forecast foreign tourist arrivals to India. 


\section{References}

[1] Anual report (2016) Ministry of tourism. Government of India.

[2] Akay, G. H., Cifter, A. and Teke, O. (2017) Turkish tourism, exchange rates and income. Tourism Economics 23(1): 66-77.

[3] Awale, M., Ramanathan, T. V. and Kale, M. (2017) Coherent forecasting in integer valued AR(1) models with geometric marginals. Journal of Data Science 15: 95-114.

[4] Apergis, N. A., Mervar, A. and Payne, J.E. (2017) Forecasting disaggregated tourist arrivals in Croatia: Evidence from seasonal univariate time series models. Tourism Economics 23(1): 78-98.

[5] Bates J.M. and Granger C.W. (1969) The combination of forecasts. Operational Research Quarterly 20: 451-468.

[6] Box, G.E.P. and Jenkins (1976) Time series analysis. Forecasting and Control.

[7] Chu, F.L. (1998) Forecasting tourism demand in Asian Pacific countries. Annual of Tourism Research 25(3): 597-615.

[8] Cho, V. (2003) A comparison of three different approaches to tourist arrival forecasting. Tourism Management 24(3): 323-330.

[9] Coshall, J. (2006) Time series analysis of UK outbound travel by air. Journal of Travel Research 44(3): 335-347.

[10] Chu, F.L. (2008) Analyzing and forecasting tourism demand with ARAR algo- rithm. Tourism Management 29(6): 1185-1196.

[11] Chen, C. F. and Chang, Y.H. and Chang, Y.W. (2009) Seasonal ARIMA fore- casting of inbound air travel arrivals to Taiwan. Transportmetrica 5(2): 125-140.

[12] Deng, J. (1982) Control problems of Grey systems. Systems and Control Letters

i. $\quad 1(1): 288-294$.

[13] Deng, J. (1986) Grey prediction and Grey decision making. Huazhong University of Science and Technology, Wuhan, China (in Chinese).

[14] Engle, R.F. (1982) Autoregressive Conditional Heteroscedasticity with Esti- mates of the variance of United Kingdom Inflation. Econometrica 50(4): 987-1008.

[15] Engle, R.F. and Granger, C.W.J. (1987) Cointegration and error correction: representation estimation and testing. Econometrica 55: 251-76.

[16] Granger, C.W.J. (1969) Causality, cointegration, and control. Journal of Eco- nomic Dynamics and Control 12: 551-559.

[17] Granger, C.W.J. (1969) Causality, cointegration, and control. Journal of Eco- nomic Dynamics and Control 12: 551-559.

[18] Granger, C.W.J. and Newbold (1974) Spurious regressions in economics. Jour- nal of Econometrics 35: $143-159$.

[19] Goh, C. and Law, R. (2002) Modeling and forecasting tourism demand for ar- rivals with stochastic non-stationary seasonality and intervention. Tourism Management 23(5). 499-510. 
[20] Hylleberg, S., Engle, R.F., Granger, C.W.J. and Yoo, B. S. (1990) Seasonal integration and cointegration. Journal of Econometrics 44: 215-238.

[21] Indian Tourism Statistics (2015) Government of India Ministry of Tourism, Mar- ket Research Division. http://www.indiastat.com.

[22] Johansen, S. and Juselius, K. (1990) Maximum likelihood estimation and in- ference on cointegration with application to money demand. Oxford Bull Econ Stat 52: 169-210.

[23] Johansen, S. (1991) Estimation and hypothesis testing of cointegrating vectors in Gaussian vector autoregressive models. Econometrics 59: 1551-80.

[24] Kim, S. H. (1988) The demand for international travel and tourism to South Ko- rea: An Econometric Evaluation of Major EconomicFactors. Unpublished Ph.D. thesis, University of Santo Tomas.

[25] Kulendran, N. and King, M. L. (1997) Forecasting international quarterly tourist flows using errorcorrection and time series models. International Journal of Forecasting 13(3): 319-327.

[26] Kim, S. and Song, H. (1998) Analysis of tourism demand in South Korea: a cointegration and error correction approach Tourism Analysis 3(1): 25-41.

[27] Kulendran, N. and Witt, S.F. (2001) Cointegration versus least squares regres- sion. Annual of Tourism Research 28(2), 291-311.

[28] Ljung, G.M. and Box, G.E.P. (1978) On a measure of the lack of fit in time series models. Biometrica 65: 297-303.

[29] Lewis, C.D. (1982) International and business forecasting methods. London: Butterworths.

[30] Lee, T. H. and Chung, K. J. (1995) Further results on the long-run demand for money in Korea: A cointegration analysis. International Economic Journal 103-113.

[31] Lee, C. K., Var, T. and Blaine, T. W. (1996) Determinants of Inbound Tourist Expenditures. Annals of Tourism Research 16: 407-428.

[32] Lim, C. and McAleer, M. (1999) A seasonal analysis of Malaysian tourist arrivals to Australia. Mathematics and Computers in Simulation 48(6): 573-583.

[33] Law, R. and Au, N. (1999) A neural network model to forecast Japanese demand for travel to Hong Kong. Tourism Management 20(1): 89-97.

[34] Law, R. (2000) Back-propagation learning in improving the accuracy of neural network-based tourism demand forecasting. Tourism Management 21(4): 331-340.

[35] Lim, C. and McAleer, M. (2002) Time series forecasts of international travel demand for Australia. Tourism Management 23(4): 389-396.

[36] Lai, D. (2005) Monitoring the SARS Epidemic in China: A Time Series Analysis.Journal of Data Science 3: 279-293.

[37] Li, G., Wong, K. K. F., Song, H. and Witt, S. F. (2006) Tourism demand forecasting: A time varying parameter error correction model. Journal of Travel Research 45: 175-185. 
[38] Martin, A. and Witt, F. (1989) Forecasting tourism demand: A comparison of the accuracy of several quantitative methods. International Journal of Forecasting 5. 1-13.

[39] Menezes, LMD Bunn, DW, Taylor, JW (2000) Review of guidelines for the use of combined forecasts. European Journal of Operational Research 120: 190-204.

[40] Nguyen, L. T., Shu, H.M., Huang, F.Y. and Hsu, M.B. (2013) Accurate forecast- ing models in predicting the inbound tourism demand in Vietnam. Journal of Statistics and Management Systems 16(1): $25-43$.

[41] Pantula, S.G., Gonzalez, F.G. and Fuller, W.A. (1994) A comparison of unit- root test criteria. $J$ Business Econ Stat 12: 449-459.

[42] Song, H., Romilly, P. and Liu, X. (2000) An empirical study of outbound tourism demand in the U.K. Applied Economics 32: 611-24.

[43] Song, H., Witt, S. F. and Jensen, T.C. (2003) Tourism forecasting: accuracy of alternative econometric models. International Journal of Forecasting 19: 123-141.

[44] Salman, A. K. (2003) Estimating Tourist Demand through Cointegration Anal- ysis: Swedish Data Current Issues in Tourism 6(4): 323-339.

[45] Song, H., and Li, G. (2008) Tourism demand modelling and forecastinga review of recent research. Tourism Management 29: 203220.

[46] Samagaio, A., Wolters, M. (2010) Comparative analysis of government forecasts for the Lisbon Airport. Journal of Air Transport Management 16: 213-217.

[47] Wang, C.H. (2004) Predicting tourism demand using fuzzy time series and hy- brid Grey theory. Tourism Management 25 (3): 367-374.

[48] World Tourism Organization (2014) Rank in Tourism (Press release). Press Information Bureau Government of India.

[49] World Travel and Tourism Council (2017) Travel and Tourism Economic Impact India (PDF).

[50] Xu, S., Wangshu, S., Jianzhou, W., Yixin, Z. and Yining, G. (2016) Using a Grey-Markov model optimized by Cuckoo search algorithm to forecast the annual foreign tourist arrivals to China. Tourism Management 52: 369-379. 
